\title{
DIVERSIDAD REGIONAL Y CARACTERES NACIONALES EN LA ESPAÑA DEL XVIII SEGÚN ALEXANDER JARDINE
}

José Francisco PÉREZ BERENGUEL

\begin{abstract}
Alexander Jardine, oficial inglés y cónsul en La Coruña, fue uno de los mejores conocedores extranjeros de la España del siglo xvıI. Su larga permanencia en el país y la «delicada» misión de espía que desempeñó en los años anteriores a la firma del Tratado Secreto de Aranjuez (1779) entre Francia y España le valieron para escribir unas Letters from Barbary, France, Spain, Portugal, \& c. (Londres, 1788), donde nos contaría sus impresiones sobre la realidad política, social y económica del país. En este libro van a aparecer muchas de sus ideas sobre las características nacionales y los principales rasgos distintivos de las diferentes regiones que visita. Su larga estancia en España, en sucesivos periodos, le permiten describir a éste como un pás invertebrado donde la práctica diaria de un cierto autogobierno (como el que se practicaba en las provincias vascongadas) es contemplada no sin recelo por el poder centralista de los gobiernos borbónicos de la segunda mitad del siglo, constituidos a semejanza del modelo francés con el que, de otro lado, también compartían una misma línea dinástica desde la victoria del duque de Anjou en la Guerra de Sucesión española.
\end{abstract}

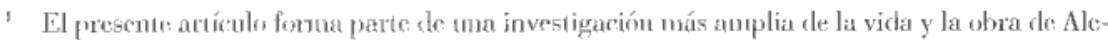
xander Jardine, que incluye la traducción al castellauo de sus wreinta y cinco Cortas de España. Para

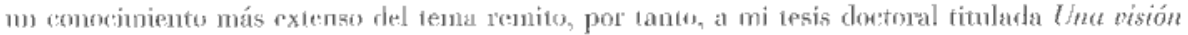

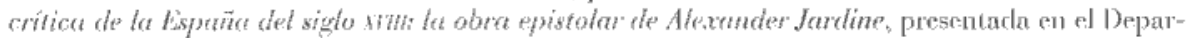
banento de: Filolegría Anglogermúnica y Francesa de la Universidad de Oviedo en mayo de 1997 
La colaburación de muchos habitantes de la antigua corona de Aragón con la causa anstracista y la posterior derrota de ésta había traído como consecuencia la pérdida de la mayoría de zus derechos políticos y la posterior implantación de los decretos de "Nueva Planta" que consagraban su nuevo grado de dependencia del poder central. No fue este el caso de las provincies vascongadas, que lograron mantener aún después del cambio dinástico gran parte de sus antiguos fueros y exenciones, a pesar del recelo constante que su mayor progreso económico solía despertar en el gobierno. De este modo, los dos mayores problemas de intcgración que tenía la corona española eran, antes igual que ahora, las provincias vascongadas y Cataluña, hasta el punto de que Jardine llega a señalar lo siguiente:

"f...] ammque los extranjeros [...] tienden a considerar como españoles a todos los súbrlitos del rey de Lispaño, [...] un vizcaino o un catolän so sienten ofendielos om esa denominación. (carta II)

Durante su prolongada estáncia en Fupaña (1776-1779), con el objeto de realizar una labor de espionaje para el Departamento de Estado para Asuntos del bur de Gran Bretaña y eom la premisa de 12 na justa recompensia en el couso de estallar un conflicto bélicu, lardine recorre el país en dos direcciones diferentes: en primer lngar, desde. Fuenterabía hasta La Coruña (en cuyo consulado establecería la residencia junto a su familia) siguiendo los caminos que commicaban la comisa cantábrica: y más darde, después de pasar ur licmpo en Portugal, partiendo de Cádiz y volviendo de nuevo a la Coruñal, atravesando casi todo el país y recorriendo parte de Andalucía, La Mancha, Madrid y Castilla y León ${ }^{2}$.

Las Vetscongadtes

Los habitantes de cstas tres provincias, a las que Jardine añade Navarra, presentaban algumas cararterísticas distintas al resto del pás. De este modo. según Jardine, consiluían una raza más fuerte y robusta y comían más carne? que los demás, lo que les asemejaba en parte a los ingleses, hasta el punto de

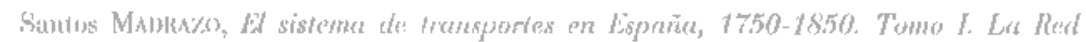

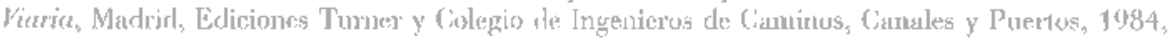

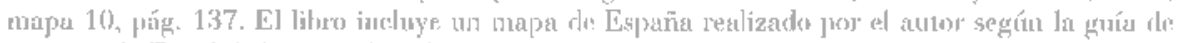

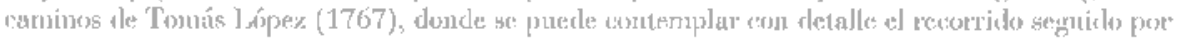
Iarcline descle Cádiz a Sautiago. 
compartir también con ellos un mismo temperamento «noble, franco y generoso» (carta II). Esto quizás habría que ponerlo en relación con la idea, ya expresada por Montesquieu, de la mayor disposición de los montañeses hacia la libertad, ya que se ven más favorecidos por la naturaleza y «no están expuestos a la conquista»". Además, en este caso, las tres provincias contaban con una administración propia y casi independiente del gobierno central, lo cual había generado, en opinión de Jardine, unos efectos positivos evidentes en su carácter, industria y población. Dicha situación había supuesto innumerables beneficios tanto para gobernantes como para gobernados, para el poderoso gobierno central y para la propia administración de estas provincias, ya que disponían de los mejores caminos y la mejor situación económica de todo el país y constituían un verdadero ejemplo para otras regiones y para otros países que, como era el caso de Inglaterra, mantenían en ese momento un conflicto abierto con sus colonias.

Jardine se sorprendería muy positivamente de encontrar en esta región una Sociedad Económica como la Bascongada, dedicada al fomento de las artes útiles y los oficios, aunque lamentaba que su éxito dependiera tanto de la figura del Conde de Peñaflorida, ya que la desaparición de éste podía conllevar el abandono de muchos de sus planes y proyectos para el desarrolto y la mejora de toda la región. Dichas provincias constituían, además, un ejemplo aislado de desarrollo industrial en relación con el resto de España, donde la abundancia de dinero hacía imposible la creación de cualquier tipo de industria o manufactura que fuera competitiva. A ello había que sumar también el acierto y la economía en la construcción de los caminos de la región, ya que éstos «se han realizado de una manera noble y económica, y sin que el gobierno, por suerte para ellos, haya tomado parte alguna» (carta IV).

Frente a este panorama tan alentador, también existían problemas que no pasaron inadvertidos a Jardine. El primero, fácilmente perceptible por cualquier viajero, era la escasez de cal y la falta de pulcritud y de acabado de sus edificios, lo cual confería a toda la región un cierto «aspecto apagado y melancólico» (carta II). Al mismo tiempo, la ubicación de sus dos principales ciudades, Bilbao y San Sebastián, resultaba inadecuada, según Jardine, y ahora era imposible de cambiar debido a la propia inercia de la administración central. Existía, además, una excesiva dependencia de la exportación del hie-

"Montrisolitu, El espirin de las leyes, traducción de Mercedes Blázquez y Pedro de Vega y prólogo de Enrique Tierne ('alván, Burexlona, Orbis, 1984, páng. 236. 
rro, aunque este "pequeño negocio" de unos doscientos mil quintales al año había producido no pocas mejoras en otros ámbitos, al grenerar una mayor demanda en la agricultura, la reforestación y la fabricación de lierranientas.

Sea como fuere, la mayor riqueza relativa de la región había despertado no pocos recelos en el gobierno central, en opinión de Jardine, y ueste gobierno resabido [...] comienza a dar muestras de un recelo mezquino e injusto hacia su prosperidad» (carta II). El mejor ejemplo de ello lo constituía el peulatino traslado de. la exportación lanera al puerto de Semtancite. De este nodo, si no so había acabado antes con dicha situación se debía tan sólo a la indolencia, la incapacidad, la casualidad y otras circunstancias adversas del gobiemo español» (carta II).

Ashuias

Después del tiempo transeurrido on las provincias vascongatlas, Jardine atravesaría Asturias de camino hacia Galicia y por tanto, sin detenerse demasiado para poder ofrecer una descripción detallade de la región. No ubstante, lo prinero que le sorprende es su extraordinaria belleza natural, a posar do las no pocas dificultades quo para un viajero debía presentar una naturaleza tan escarpada y el mal estado general de los caminos. Su incursión en Asturias as relatada del siguiente modo:

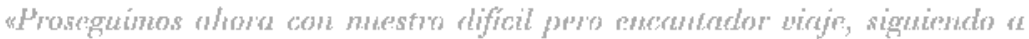
neenufo la hina costera, a través de senderos estrechos, al borde de terribles precipirios, y con d hortor añadilo de enconfrarse rotulados los sitios dond" hombres, malas y demás se han despeñado, destrozándose pn pedazos antes

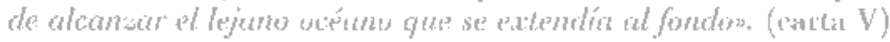

Ensegnida surge la comparación de cste paisaje con al de Vizcaya, que acabalua de dejar atrás:

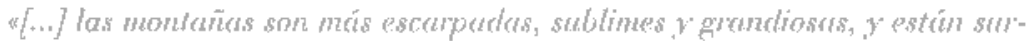

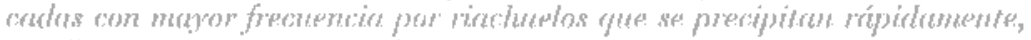
y valles estrechos qua estân. fanqueatos por bosques y peñascos. La mente

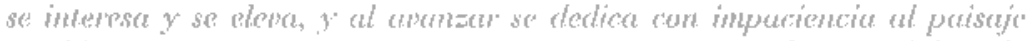

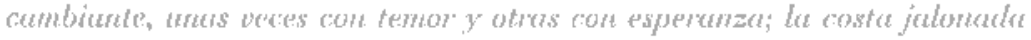
de pequeñas bahus y rias y salpicada de promontorios racoson, las pesquerúus de sulmón y man escasas y pobres aldens desperdigadas situadas en mu emplazamiento romántiou completun el pumoremus. (carta V)

Y del paisaje al paisanaje. Una vez nás, Jardine compararía los hahitantes de esta región con los de Vizcaya de la cual los asturianos no saldrían tan bien parados: 
"Los habitantes son fuertes y rísticos, annque no tantos y tan laboriosos como los vizcaimos; una raza visiblemente distinta, más orgullosa e indolenter. (carta V)

Lo que mas parecía sorprenderle era el fuerte parecido nntre los asturianos y los antiguos romanos, cuyo origen, señalaba, habría que buscarlo en la historia y remontarto a aquella época en la que Asturias no era nacla más que una perpuña parte del Imperio. Según Jardine, los asturianos eran preferidos como criados a todos los demás, por sus scualidades de homadez y fidelidad» (carta V). Esta afirmación implicaba el conocimiento de una realidad social que afectó a muchos asturianos y montañeses a lo largo del siglo XVIII, como cra la predilección que se tenía en la corte para emplearlos en el oficio de la librea.

Por lo que respecta al desamollo económico de Asturias, Jardine destacaría la posibilidad única que tenía la región de introducir manufacturas « de manera provechosa”, ya que su aislamiento geográfico del resto de España había facilitado, por fortuna, una menor afluencia de dinero procedente de las colonias y que había hecho imposible la croación de cualquier tipo de indusiria en el resto del país, con escasas excepciones. Por último, Jardine no dejaría de sorprendernos con su propuestá de otorgar al Príncipe de Asturias la administración efectiva de esta región, con el fin de que esto pudiera scrvir para "promover la felicidad de esas gentes, así como de aprendizaje en el arte de gobernar un reinos (carta V). Habrían de pasar otros quince años para que Jardine volviera a pisar tierra asturiana, tras un azaroso viaje en barco deste Inglaterra, antes de poder ejercer como nuevo cónsul de La Ciormina. Giacias a ello, pudo conocer a Jovellanos, que le fuc presentado por mediación del vicecónsul inglés en Cijón, Edward Kelly, y mantener una fructífera relación con és1e que habría de durar tres anos y a ravés de la cual Jovellanos llegó a conseguir no pocos libros y revistas inglesas que cra imposible adquirir en España. así como algunos instrumentos para su Real Instiluto de Gijón. Eu su correspondencia se confroutarían dos formas distintas de ver el mumdo de finales de siglo: una, la de lareline, partidaria de una reforma imnediata del sistema politieo vigente; y otra, la de Jovellanos, más posibilista y partidaria, como sabemos, de la reforna progresiva y paulativa, sin prisa pero sin pausat.

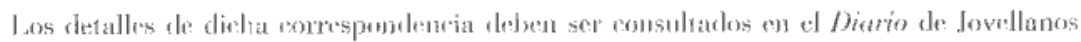

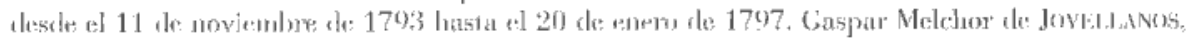

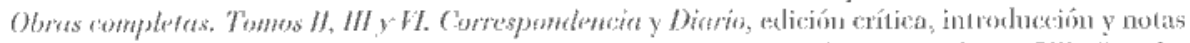

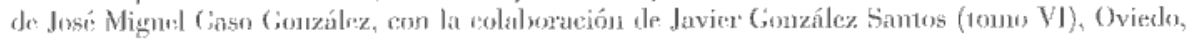

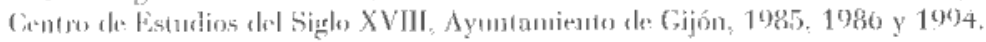


La región española a la que más atemción le presta Jardine es, sin duda, Calicia, y esto se debe al hecho de ser en ella donde había lijado su lugar de residencia. Lo primero que despierta su atención es la menor estutura de sus liabitantes:

astos gallegos parecen en su mayoria pobres y harapimtos, constituyen una raza de hombres pequeños o bajos [...] imagino que [...] por su costumbre de acompro ragas subre la cubezan. (carta VI)

Su parecido físico con los portugueses es grande y, eru su opinión, éste también se hace extensible a "las costumbres. los nombres y el idioma». En cuanto a su carácter, Jardine presenta a los gallegos cono aseres dóciles, obedientes, mezquinos y harapientos», y los compara con los judíos pobres de Gibrattar. No obstante, quizás como contrapunto, no desaprovecha ninguna ocasión para resaluar la gran laboriosidad de los gallegos, aumpue lanentara que la misina se hiriera cou escaso «espíritu " desireza» (carta VI).

La pobreza secular que padecían sumonía un gran obstáculo para su desarrollo y verúa condicionada por diversas cacencias de carácer estrucitural. Des este modo, nno de los problemas más acuciantes pra la escasa y pésima infraestructura viaria de la región:

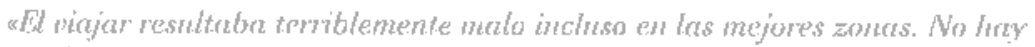
caminos, ni posadas, ni personas que ressmpeñen ningün oficho rle forma aceptable; salvo mulfitud de puestos draduana, con sus fincionuros, por

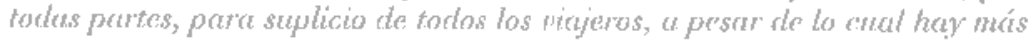
contrabando agui gue en mingrín otro hagum. (curn XXV)

Otra cuestion importante era el estado actukil de la agriculiura y la ganadería. Jardine se sorprendia de la escasa producción de su agricultura, a pesar de cultivar la mayoría de las tierras de la región, incluso las situadas cn las laderas de las montañas. La razón de esto había quo buscarla, según Jardine, en el monocultivo del centeno y en el abandono subsiguiente de otros productos «mpjores», como eran las patatis y el hern. Este último portía servir, advnús, para alimentar mejor a su cscasa y pobre ganadería y para increnncotar su número. Unicamente las vacas que se criaban en las tierras bajas de la región constituían una raza aceptable y cran exportadas al resto de Espana. Su mala alimentación lleva a Jardine a señalar lo siguienie:

"Et que perdieran agui una gran cartidad de sus vecas debido a la escasuz no serín tan sorprendente como el que tantas sobrevitieran al invierno con una provisión tan insuficientem. (carta VI) 
Al mal estado de la agricultura y la ganadería se sumaba también la falta de infraestructura industrial, debido a la afluencia masiva de dinero procedente del comercio con las colonias, especialmente ahora que el gobiemo había abierto éste a los puertos de El Ferrol y La Coruña.

Estos tres problemas se veían, además, agravados por el excesivo poder que tenía la Iglesia en la región, ya que ésta era omnipresente y condicionaba mucho la forma de vida de sus habitantes, más aún que en ningún otro sitio del país. La capital de la región, Santiago de Compostela, se había convertido, para Jardine, en la capital de la superstición, y era el sitio donde mejor se podía «contemplar el poder de la Iglesia» (carta XII). La peregrinación anual de fieles a la catedral de Santiago había disminuido mucho últimamente, aunque aún seguía originando «un gran desorden y ociosidad durante el verano» (carta XXV). Otra prueba de su poder la constituía el gran número de edificios religiosos en la región, en contraste con su extremada pobreza.

Pero no todo serían críticas y Jardine no dejaría de señalar aquellas cosas que funcionaban mejor en Galicia que en otras partes del país, esto es: el número de habitantes de la región y su modelo de propiedad de la tierra (los foros). De este modo, señalaba que, aunque no fueran ciertas las cifras que estimaban en un millón y medio el número de habitantes de la región, ésta superaba con creces la densidad de otras partes de España, lo cual, unido a su gran pobreza, obligaba a una gran parte de la población a emigrar al resto del país o a Portugal. La razón de esta mayor densidad se basaba, de acuerdo con Jardine, en la mayor fecundidad de las mujeres gallegas y en su mayor valentía a la hora de traer hijos al mundo. Además, allí donde se asentaban, los gallegos resultaban sextremadamente útiles en la agricultura, y en una diversidad de labores domésticas que los naturales más pobres y harapientos de aquellas tierras no quieren realizar por excesivo orgullo e indolencia» (carta VI). Galicia exportaba también algo distinto a la mano de obra e igualmente «de gran importancia»: sus vacas. Por todo ello, aunque fuera menos conocida por los diferentes viajeros debido a sus malas comunicaciones con el resto del país. Jardine la consideraba «la región más importante de España, si exceptuamos, quizás, a Cataluña» (carta XI).

\section{Andalucia}

Jardine se nos presenta como un precursor de lo que después se convertiría en la leyenda romántica de Andalucía, destacando el gran interés que despertaba su visita para cualquier viajero de paso por España, «tanto por el 
humor, el dialecto, el ingenio y la urbanidad de sus habitantes, como [...] por la prosperidad relativa de la r'egión» (carta XIV). No obstante, la realiclad pronto le haría ver las cosas de una manera menos optimista, sobre rodo cuando se adentra por la región y se sorprende de su gran aridez, su poco cultivo y su población escasa y desperdigada, al estilo de las aldeas árabes quo había conocido ess su visita a Marruecos. De un panorama tan desalentador. sólo se salvarían las dos colonias alemanas creadas por Olavide y la vierra dedirada al cultivo del olivo, ya que la rentubilidad de ésta se pouía de manifiesto en la proliferación de maquinas y de molinos destinados a la producción del aceite.

Algunes de las cartas del libro apareeen escritas en Cádiz. La mayor riqueza de esta ciudad y su privilegiasta situación comercial (después de haber detentado durante muchos años el monopolio del comercio do Espana con las colonias americanas) detejmina algunos de sus rastos distintivos:

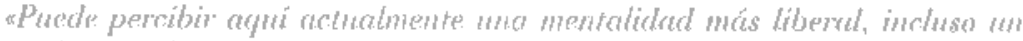
ranréter indinado al lijo y al vicio distinto al del resto de la narión, anas costrambres más alegres y ana mayor confanza, crédito y soxiabilidal enter los hombres $[. .$.$] . (carta XIV).$

Su cstuncia en esta ciudad lo lleva a denunciar la actuación del administrador de rentas del puerto, al que acusaba de exceso de cello pror intentar gravar todos los aranceles exigidos por el Estado, ya que, señalaba Jardine, "tuvimos la mortificación de ver algunas do sus hogueras de magníficos prorductos ingleses» (carta XIV). En cuanto a Córdoba, destaca su buen emplazamiento a orillas del río Guadalquivir, la fertilidad de su vega y la cerranía de «as montañas sublimes de Sierra Morenck, llenas de bosques, agua y una diversidad de suelos y de lugares encantadoress (carta XIX). A pesar de ello, la opinión que. te merece la ciudar difiert mucho de este bucolismo, ya que riste "no presente ahora más que un aspesto pohre y melancólicon y parece sunida en la inclolencia, la sucicdad, las ruinas, la miseria y los conventoss (carta X]X). De cualquier manera, la predilección que Jardine, al igual que otros compatriotas suyos, sentía for Andalucía no podría feflejanse nejor que con las siguientes patalyras:

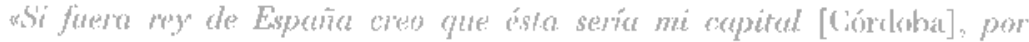

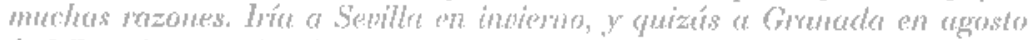

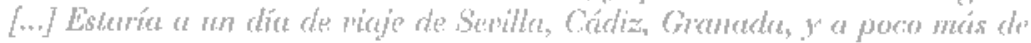

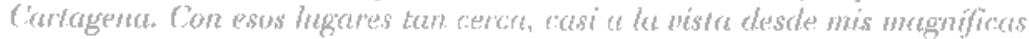

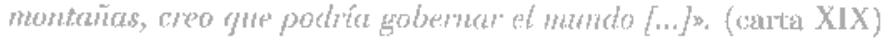


Jardine peca de ofrecer una inagen un tanto tópica y superficial de La Mancha, motivada quizás por su escaso conocimiento de la región, ya que es probable que sólo constituyera un lugar de paso en su camino hacia Madrid. De cualquier modo, asocia ésia acertadamente con la figura de Don Quijote y señala algunas de sus características, como la simplicidad, la pobreza, la alegría y la música, que, en su opinión, sirven para describirla. Enseguida veremos por qué. Lo que más le llamaba la aucnción dentro de la región era la proliferación de un tipo de canciomes típicas llamadas aseguidillas", tue surgían de un modo natural e improvisado y que le resultaban eencantadorass. Por lo demás, el campo seguía siendo tan amarronado y monótono como el resto de las llanuras del interior: "seco, desnudo, de arcilla marrón, sin rastro de verde, y donde apenas se deja ver un arbusto salvo cuando los viñedos tienen hojas» (carta XXI). No obstante, la naturaleza, señala Jardine, haciendo gala de ima gran sabiduria, se encargaba de equilibrar este panorama tan sombrío al proporcionar a sus habitantes una abundancia de buenos alimentos y una alegría que les permitía vivir sin grandes esfuerzos o incomodidades:

"Pero en estos potures y uscasos pueblos de areilla hay abundencia de buen

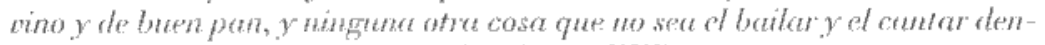
tro y fuera de cesse fodas las tardess (carta XXI).

Por lo gue respecta a Madrid, lardine remite a otros autores, sin especificar cuales, para aquellas personas que deseen encontras ma descripción completa y detallarla de la capital. La única observación que nos ofrece sobre su aspecto se refiere a que «ahora ss una ciudad aceptablemente limpia, con unas cuantas calles y edificios buenos, pero sin alrededores agradables» (carta XXII). Tan sólo la apariencia lísica de sus habitantes es objeto de una mayor atención pos' su prarte:

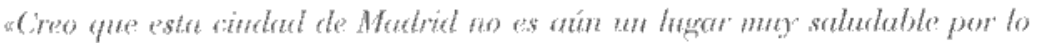

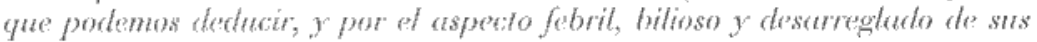
habitantes; no sem por lo genenal pessonas ni corpulenlas ni gratpas, y tienen un cierto aspecto de descomtento o resignación callader, o algo a medio camino de anbas, que resulta más fuecil de observarque de explicar's. (carta XXII)

Castilla y León tampoco scría merecedora de mucha mayor consideración. Lo que más le sorprenclía era su extrema pobreza, su despoblación y la falia casi total tle vegetación:

"No encuentro mucho que mereza la pena ser ropiado y temido en auenta en las. "anotaciones" de diversos viajes por las ahora desiertas llamuras de 
Castilla la Viejor y León, donde ciertumente hay tou poco que ver, at margen de algunos rebaños desperdigados de ovejas y unas cuantas cuududes y pueblos de arilla may alejados entre si, llenos de suciedad. polreza y inins, y que parecen haber sido quemados recientementex. (cata XXII)

Buena prueba de ello era el escaso número rie viviendas yue disporían de ventanas de cristal, incluso en las ciudades lancras. El panorama de entonces no era más que el vestigio desolador de su anterior grandeza, de la cual sólo quedalban ahora las ruinas, la suciedad y la pobreza. Denuro de lat revión, destacaba, en su opinión, la cindad de Burgos, tal vez por laber sido anterionmrne: «la residencia de sus principes» (carla XXIJ). No obstante, su úrnica esperanze de futro parecía proceder de la construceiún de caminos y carrales que permitieran transportar a las provincias marílimas los cereales que producían, pero esto «hasta ahora ha resultarto imposible» y, según Jardine, no era probable gut pudisa remediarse pronto.

El paso por León trat consigo la reaparición de alas colinas verdes, el busque, el agua, la polblación y muchas bellezas» (carta XXV), hasta el purto de

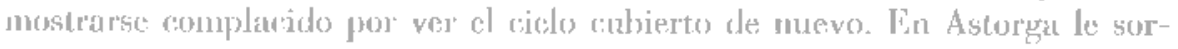
prende la presiencia de los marugatos, "quienes son con probabilidad algún vestigio de una raza árabo o mestiza» (carta XXV). listus se distirguían por su grant laboriosidad y por la pericia con la que desempeñaban las ires prolesiones de arriero, granjero y comerciarite, en las que, con el liempo, se habían ganado una gran reputación de honrackez. Por niltimo, la cencanía de 'Toro le serviría para halagar los vinos que ste recogian en está zoná, ya que eran normalmente «fuertes y do bucn cuerpo», anuque quizés pudiesen mejorar con lá syuda, esta vey sí, de Ios framones, que eran los mayores expertos en ello. lira, por tanto, de lamentas la indiferencia y la despreocupación que existía en su elahoración, al igual ipue ocurría «enn todo lo demás», máxime cuando con ello se evitaha que España pudiera disponer ade lina gran variudad de vinos excelentes: (carta $X X V$ ).

Tha ver, descritos algunos de los aspectos difereneiales apreciados por Jardine en sus distintos viajes por España, el autor apuntaba también el riesgo de que dichas diferencias se profundizaran altificialmente con una clara intencionalidad foblítica, como pone de manifiesto en la siguiente afirmación:

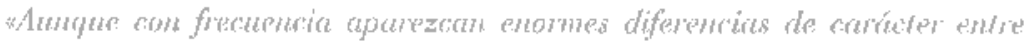
teriones y provincias recinas de la misma latitud, como ocmre en estrt nación entre los catalumes, los valencianos y los andahee's, existen también mrís semejanzas que las que ellos desent observar puesto que, al ighal que

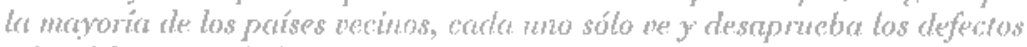
y las diferencires de los demás. (carta VI) 
Es el momento, pues, de profundizar un poco en la posible existencia de algunos caracteres nacionales que pudieran ser compartidos por la mayoría de. los habitantes del país. Este tema suscitaba un enorme interés entre muchos pensadores del siglo Xvil y estaba vinculado en no pocas ocasiones a un cierto determinismo ambiental cono el ya señalado por Jardine. Uno de los tópicos más extendidos en este siglo era la atribución al carácter de los españoles de dos rasgos específicos: el orgullo y la indolencia. De este modo, Montesquieu los había descrito en una de sus Cartas Persas (la número LXXVIII) como personas excesivamente altivas, graves y arrogantes, con gran desprecio a los demás, especialmente hacia los franceses. Esto se ponía de maniliesto, en su opinión, en la gran preocupación que existía en el país y en sus colonias por al linaje y la pureza de la sangre, y en la consideración del trabajo como algo indigno:

aPorque se ha de saber que crando goza uno cierta prerrogativa en España [...] ya no trabaju, interescindose su pundonor en el sosiego de sus miembros. Quien se está sentado diez horas al dia consigne cabalmente doble aprecio que quiru no lo está más que cinco, poryuc se granjea la nobleza repantigrándese en una sillar".

El único rasgo positivo de su carácter parecía ser el de la houradez, puesto que «la bnena fe de los españoles ha sido famosa en todos los tiempos»". Pero incluso ésta podía traer también consigo efectos no deseados y muy negativos para el país, ya que la confiamza de las demás naciones al otorgar a los españoles la exclusividad del comercio con Cádiz sólo redundaba en el propio beneficio de éstas y por tanto, como señalaba William Robertson, «esa honradez, que es el orgullo y el rasgo distintivo de la nación, contribuye a su ruinas?

Para Alexander Jardine, sin embargo, esta apreciación tan negativa del pensador francés sólo podía deberse al desprecio casi generalizado que muchos franceses de la ćpoca sentían hacia todo lo español. Por esta razón, Jardine siempre acusaría a los borbones y a la influencia francesa de ser los principales responsables de la mayoría de los males del país. En su opinión, esta influencia venía impuesta desde el poder político y no tenía en cuenta la gran dilerencia de carácter contre las dos naciones:

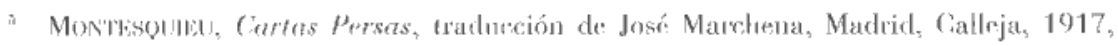
píg. 170.

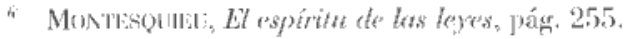

+ William Roblítson. The History of America, Iondon, Cadeli \& Davies, 1808, vol. IV. pág. ?6.
} 
"Los habitamies de Firancia y los de España, con un temperamento fam opuesto, necesitn probablemente formas diferentes de gobiemo, pero ahom tienen easi la misma, yodenos conchir, por tanto, que una de ellas no es la adecuarla y es probable que sea la ke Españan. (carta X)

Además, según Jardine, esta predisposición contra los franceses de la que sf: quejaha Montesquieu había comenzado a desaparecer, toda vez que España se encontraba en un estado de dependencia y subordinación frente a Francia derivado en gran medida del reciente cambio dinéstico. Ante esta situación, lo gue España necositaba, señala Jardine, er'a un gobierno de libertad y seguridad que pusiera lin al estado actual dr indolencia y de intolerancia religiosa, ya que «el país está lleno de caráteres inłividuales valiosos, o, mejor dicho, de materiales con los que estos se pueden formar ex el momento en que se les neresites (carta XVIII), Pero alurturadamente, en su opinión, la degradación moral y política no había conseguido todavía aculoar con col comporlamiento franco y hourado qu: carecturizabat a los españoles y. por tanto, éstos seguían siendo. junto con los ingleses, mo de los curacteres modemos más destacarlos de tonda Finropa.

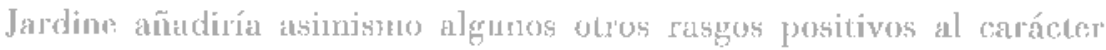
espanol, aparte de los ya mencionados anteriormente por Montesquieu, conno eran la generosidarl. da resulnción, la perocverancia y la eduanimidad. Además del sentido del humor y la "wractias especial do la gente, la cual logra enganchar y atraer "a los que logran penctrar en sul gusto y espíricu, pero que hasta que eso ocur'a resulta incomprensible para el cxtranjero o el que viene de pasos (carta XXT). Do este modo, los españoles, y especialmente los andaluses, disponian de un gran ingenio, aunque hubiera que lamentar su preferencia por el de estilo más chabacano y grosero. Éste resillaba eu todo caso preferilule a la cxresiva rigidez (Jue mostraban los ingleses, a los cuales iba dirigida la siguiente exelemación: "Dios nos libre de que nos volvanos personas demasiado difíciles de agreturs (carta XVILl). La atracción que despiertan las cosnumbres, el ingenio y la forma te ser de los españoles sólo podía ser percibida

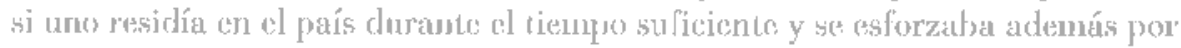

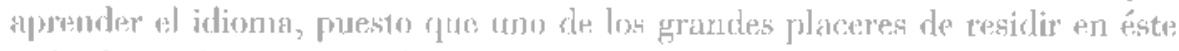
radicaba en la conversación. Para Jardince, al estardo de decadencia en el que estaba sumirla la nación nada tenía yue ver son el carácter de la gente puesto que, sn su opinión, "los stpañoles son de natudal una raza de personas audaces, impertumbables, alegres y perspicaces, y no veo nada en su carácureriginal que resulte muy imomparible con el joregreso de la industria y las mejoras quo cu owos lugares parecen algo consustancial a los hombres en soriedady (carta XXVI). Por tanto, la causa de tante decadencia habría que buscarla nús 
arriba, en la misma forma de gobiemo, principal responsable del establecimiento de una estructura de depravación y de ignorancia, alimentada por la fuerza de la costumbre y que convertía a los estamentos más bajos de la sociedad en indolentes e improductivos. Las palabras de Jardine al respecto dilícilmente podíau ser más claras y contundentes:

aspero huber dejato claro que se trata del major pueblo posible bajo el peor tipo de gobierno de los que existen en liuropa; y que las cualidades morales de los españoles pueden considerarse como ingredientes de la máxima calidad de entre los que componen el carcicter humanos. (carta XXXIV)

I Iemos tenido ocasión de comprobar cómo Jardine sentía predilección por el norte de España, siendo en estas regiones del Cantábrico doude parecía encontrarse más agusto y conforme. En ellas, la aridez de las mesetás del incerior del país se habían ido tomando progresivamente en un verdor permanente y una abundancia de agua y cultivo, en definitiva, en un paisaje mas parecido al inglés. Quizás por esta razón aceptara con agrado, unos cuantos años más tarde, ser nombrado cónsul en La Coruña, a pesar de la dificultad de ejercer dicho cargo en un puerto espanol de tanta importancia estratégica. Y quizás también por ello desearía pasar los últimos días de su vida en Calicia, una vez acabada su misión allí y cuando su país se encontraba en guerra con España. Su grave enfermedad, la avanzada edad y el recelo que su presencia despertaba en las autoridades expañolas, cn especial en el gobernador militar de Ia Coruña, el francés Desmaisieres, hicieron el resto y Jardine se vería abocado a terminar sus días a escasa distancia de la frontera española (Valença do Minho), poeo tiempo después de haber sido expulsado del país y obligato a viajar sin descanso y en condiciones de extrema dureza".

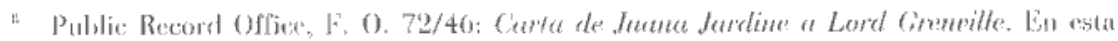

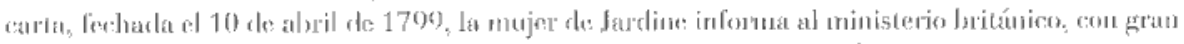

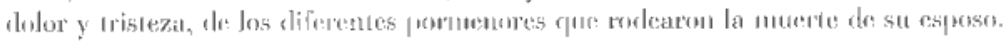

